\title{
"Mit syns selbes hand (...) auch vil andere erbar lude ermordet" - Die Verwertung der Absetzungsurkunde Wenzels IV. in der reichsstädtischen Chronistik des
}

\section{Jahrhunderts}

\begin{abstract}
"With his own hands he though killed a lot of respectable people" The deposition letter of Wenceslas IV. and its use in the $15^{\text {th }}$ century chronicles from imperial towns
\end{abstract}

Klára Hübner / huebnerk@mail.muni.cz

Ústav pomocných věd historických a archivnictví FF MU

\begin{abstract}
The bad fame of bohemian king Wenceslas IV, which was deposed by the roman electors in 1400, derives also from their well composed deposition letter, since it became the most important explanatory reference to the contemporary historiographers in the Roman Empire. The article enlightens its different influence phases as well as the slow transformation of its legal arguments into a spectrum of defaming narratives.
\end{abstract}

\section{Keywords}

Late middle ages, Wenceslas IV, defamation, political narratives, Roman Empire, Czech lands 
Erinnerungen, die mit Hilfe von Urkunden wachgehalten werden, müssen - wie in diesem Band schon mehrfach erwähnt - nicht zwingend positiver Natur sein. Ein Beispiel dafür, wie sich ihr Inhalt durch historiographische Interpretation dauerhaft in negative Memoria verwandeln lässt, stellt auch jene Urkunde dar, mit welcher die Rheinischen Kurfürsten am 20. August des Jahres 1400 König Wenzel IV. als Reichshaupt abgesetzt haben. ${ }^{1}$ Am Anfang dieses schriftlichen Verwertungsprozesses stand indes ein mündliches und visuelles Ereignis: Am besagten Tag bestieg Erzbischof Johann II. von Mainz in Oberlahnstein einen eigens für diese Gelegenheit errichteten Urteilssitz, um aus dieser symbolischen Perspektive - man befand sich schließlich in Sichtweite des Krönungsstuhls von Rhense - die Absetzung des Luxemburgers zu verkünden. Dies geschah, wie mittlerweile bekannt ist, in einer symbolischen Umkehrung des Krönungsrituals und ebenfalls publice ${ }^{2}$, also vor einer ausgewählten Gruppe von lokalen Herren, verbündeten Fürsten und rheinischen Städteboten sowie mehreren Notaren, die das Gesagte einerseits bezeugen sollten ${ }^{3}$, andererseits auch gewillt waren, die Kunde von diesem nicht alläglichem Rechtsgeschäft schnell zu verbreiten.

Schon seit Mitte der 1390er Jahre hatten die geistlichen Kurfürsten immer offener gewagt, sich gegen das ungeliebte Reichsoberhaupt in Stellung zu bringen. Die zeitlichen Umstände waren günstig: Der römische König Wenzel IV. war schon länger nicht mehr im Reich gewesen. Ein langwieriger Streit um Mitbestimmungsrechte, zwischen ihm und den böhmischen Magnaten, die 1394 in einer kurzen Gefangennahme gipfelten, hielten ihn in Böhmen zurück. ${ }^{4}$ Zudem war die politische Lage zwischen den böhmischen und mährischen Nachkommen Karls IV. angespannt bis unübersichtlich. ${ }^{5}$ Doch

1 Vgl. dazu: Deutsche Reichstagsakten unter König Wenzel (1397-1400) (= RTA ÄR). III. Hg. von J. Weizsäcker. München 1877, Nr. 204-207, S. 254-266, hier Nr. 204, S. 254-260. Dieser Beitrag entstand im Rahmen des vom tschechischen GAČR geförderten Projektes „How to destroy a king's reputation. Formation and Spreading of Medieval (Anti)royal Propaganda - The Case of King Wenceslas IV. (1361-1419)“ (Nr. 1614990S).

2 Zur Bedeutung der öffentlichen Inszenierung von Königsabsetzungen im Spätmittelalter vgl. Rexroth, Frank: Um 1399 - Wie man einen König absetzte. In: Die Macht des Königs. Herrschaft in Europa vom Frühmittelalter bis in die Neuzeit. Hg. von B. Jussen. München 2005, S. 241-254, ders.: Tyrannen und Taugenichtse. Beobachtungen zur Ritualität europäischer Königsabsetzungen im späten Mittelalter. Historische Zeitschrift 278, 2004, S. 27-53; die strafrechtliche Relevanz einer öffentlichen Absetzung liefert Schnith, Karl: Gedanken zu den Königsabsetzungen im Spätmittelalter. Historisches Jahrbuch 91, 1971, S. 309-326.

$3 \quad \mathrm{Zu}$ den grundlegenden Arbeiten über die Kurkölner Notare und ihre Verbindungen zum Hof Ruprechts von der Pfalz gehören immer noch Moraw, Peter: Beamtentum und Rat König Ruprechts. Zeitschrift für Geschichte des Oberrheins 116, 1986, S. 59-126; ders.: Kanzlei und Kanzleipersonal König Ruprechts. Archiv für Diplomatik 15, 1969, S. 428-531; ders.: Gelehrte Juristen im Dienst der deutschen Könige des späten Mittelalters (1273-1493). In: Die Rolle der Juristen bei der Entstehung des modernen Staates. Hg. von R. Schnur. Berlin 1986, S. 77-147.

4 Eberhard, Winfried: Gewalt gegen den König im spätmittelalterlichen Böhmen. Adeliger Widerstand und der Ausbau der Herrschaftspartizipation. In: Königliche Gewalt - Gewalt gegen Könige. Macht und Mord im spätmittelalterlichen Europa. Hg. von M. Kintzinger - J. Rogge. Zeitschrift für Historische Forschung (= ZHF), Beiheft 33. Berlin 2004, S. 101-118.

5 Zu Wenzel allg. vgl.: Bartoš, František Michálek: Husũv král. Jihočeský sborník historický 13, 1940, S. 1-15; Spěváček, Jiří: Václav IV. (1361-1419). K předpokladi̊m husitské revoluce. Praha 1986; zu Jobst von Mähren vgl. Štěpán, Václav: Moravský markrabě Jošt. Brno 2002. Vertiefende Studien, die sich den Konflikten zwischen den Mitgliedern der Luxemburger Dynastie widmen würden, fehlen bislang. 
erst als sich Wenzel 1397 entschloss, in der festgefahrenen Schismafrage eine bilaterale Lösung mit dem Französischen König Karl VI. anzupeilen, begannen auch die geistlichen Kurfürsten um ihre langsam gewachsene Rolle als Verfechter einer föderativen Reichsherrschaft zu bangen. ${ }^{6}$ Als Vertreter der römischen Papstmacht fühlten sie sich in der besagten Frage übergangen. Ihren politischen Bestrebungen liessen sie nun auch öffentliche Maßnahmen folgen; diesen, von František Graus als „Propagandafeldzug“ betitelten Versuch ${ }^{7}$, Wenzels Herrschaft gezielt und öffentlich zu diffamieren, leitete im Sommer 1397 eine Reihe von Beschwerdebriefen an den König ein. ${ }^{8}$ Ihren vorläufigen Abschluss fanden sie im Frühjahr 1399, als erstmals auch die Frage seiner möglichen Absetzung erörtert wurde. ${ }^{9}$

Der Akt von Oberlahnstein war also nicht die überstürzte Handlung einiger besorgter Kurfürsten, die um die Integrität des Reiches bangten, wie es noch in der älteren deutschen Historiographie dargestellt wird ${ }^{10}$, sondern Ergebnis mittelfristiger politischer Planungen, bei denen zunächst einmal alle Optionen offengehalten werden sollten. Ihre finale Umsetzung lässt indes eine gewisse Unruhe erkennen, was sich vor allem an der Eile manifestiert, mit welcher die verlesenen Anklagepunkte im Anschluss an den rituellen Akt verschriftlicht und verbreitet wurden. Denn bis zur allgemeinen Anerkennung von Wenzels Absetzung riskierten die oppositionellen Reichsfürsten selbst als Majestätsverbrecher abgeurteilt zu werden. ${ }^{11}$ Dieser Druck, doch auch die Nervosität der Beteiligten ist dank den älteren Reichstagsakten Weizsäckers immer noch nachvollziehbar. Neben der politischen Stimmung dokumentierte die Materialmenge allerdings auch die Schlagkraft der Kurkölner Kanzlei. Denn der Aufruf zur Aufkündigung der Vasallentreue gegenüber Wenzel muss bereits am 20. August in zahlreichen Exemplaren an alle Reichsangehörigen verschickt worden sein - und das, obwohl Ruprecht von der Pfalz erst am 21. August in Rhense gekrönt werden sollte. Und an diesem Tag wurde wohl

6 Garnier, Claudia: Die Politik der geistlichen Kurfürsten im Spätmittelalter im Spiegel ihrer Einungen und Verträge. Der „Mainzer Kurverein“ (1399) und der „Binger Kurverein“(1424). In: Erbeinungen und Erbverbrüderungen in Spätmittelalter und Früher Neuzeit. Generationsübergreifende Verträge und Strategien im europäischen Vergleich. Hg. von M. Müller - K.-H. Spieß - U. Tresp. Studien zur brandenburgischen und vergleichenden Landesgeschichte 17. Berlin 2014, S. 96-115; dies.: Die Ordnung des Reiches. Die Position des Herrschers in der Goldenen Bulle in der Wahrnehmung bis 1400. In: Die Goldene Bulle. Politik - Wahrnehmung - Rezeption. Bd. 1. Hg. von U. Hohensee u.a. Berichte und Abhandlungen. Berlin-Brandenburgische Akademie der Wissenschaften Sonderband 12. Berlin 2009. S. 197-240.

7 Graus, František: Das Scheitern von Königen. Karl VI., Richard II., Wenzel IV. In: Das spätmittelalterliche Königtum im europäischen Vergleich. Hg. von R. Schneider. Vorträge und Forschungen (= VuF) 32. Sigmaringen 1987, S. 17-39, hier S. 21.

$8 \quad$ RTA ÄR III, Nr. 9, S. 22-23.

9 Vgl. Sthamer, Eduard: Erzbischof Johann II. von Mainz und die Absetzung König Wenzels. Jena 1909; Walther, Helmuth G.: Das Problem des untauglichen Herrschers in Theorie und Praxis des europäischen Spätmittelalters. ZHF 23, 1996, S. 1-28.

10 Allen voran durch Theodor Lindner und seine Jenaer Schule, vgl. ders.: Geschichte des deutschen Reiches unter König Wenzel. 2 Bde. Braunschweig 1875-1880.

11 Schnith, K.: Königsabsetzungen, S. 315-316. 
auch die Absetzungsurkunde Wenzels IV. zunächst auf Deutsch verschriftlicht, damit erst einmal der rechtliche Status quo festgehalten werden konnte. ${ }^{12}$

Wie immer, wenn im Spätmittelalter Könige abgesetzt wurden, galt es das Dokument so zu gestalten, dass einerseits der Anschein eines Prozesses vermieden wurde. Andererseits musste so argumentiert werden, dass die gegen den König vorgebrachten Gravamina sowohl der kirchenrechtlichen Grundlage standhalten konnten, als auch auf konkrete Anschuldigungen anspielten, die als Fakt, Halbwahrheit oder auch nur Gerücht schon länger in Umlauf waren. Der juristische Unterbau bestand seit dem 13. Jahrhundert im Wesentlichen im Nachweis, der Abzusetzende sei ein rex inutilis, der sich mindestens eines Verstoßes gegen das kanonische, 1245 in der Bulle ad apostolice dignitatis Innozenz' IV., festgeschriebene Quartett Meineid, Friedensbruch, Sakrileg und Häresie geleistet hätte. ${ }^{13}$ Da Letzteres auch eine Frage der politischen Auslegung war, galt es die vorgebrachten Vorwürfe offen zu formulieren. Die Narratio der Urkunde enthält sechs verhältnismäßig unspezifische Anklagepunkte gegen Wenzel - er habe als König seine Herrscherpflichten vernachlässigt und sich nicht um die Behebung des päpstlichen Schismas bemüht. Ferner hätte er Mailand zum Herzogtum erhoben, ohne den notwendigen kurfürstlichen Willebrief vorzuzeigen. ${ }^{14}$ Zudem hätten sich zahlreiche Städte, vor allem im Westen des Reiches, von ihm abgekehrt. Auch hätte er sich mit eines Königs unwürdigen, ja lasterhaften Personen umgeben, das Reichsgut schlecht verwaltet und Kriege verursacht, Blankovollmachten - membranen - gegen Gebühren ausgestellt und sei überhaupt alles andere als ein „Mehrer des Reichs“ gewesen. Abschließend wird es dann merkwürdig, denn im sechsten Anklagepunkt steht, er hätte er auch syns selbes hand und unter Mithilfe ander uebelteder die er by yme hait erwirdige und bidderbe prelaten pfaffen und geistliche lude und auch vil andere erbar lude ermordet erdrenket verbrandt mit fackelen und ys jemerlichen und unmensslichen widder recht getötet. ${ }^{15}$ Nachdem nochmals beteuert wird, Wenzel habe sich jeder Erklärung von seiner Seite widersetzt, folgte abschließend die durch den Mainzer Erzbischof vorgelesene Depositionssentenz. Zuletzt wurde die Urkunde durch ihren Hauptverfasser Heinrich Stalberg und sechs weitere Notare bekräftigt. Um die Vollständigkeit des politischen Anspruchs zu erhärten, wurde am selben Tag auch eine lateinische Übersetzung angefertigt, die vermutlich auch für

12 Der einzige Unterschied zur deutschen Urkunde besteht in einer verkürzten Widergabe der einzelnen Anklagepunkte, vgl. ebd., S. 316-317, RTA ÄR III, Nr. 204, 205.

13 Diese ging aus dem Streit zwischen dem Staufer Friedrich II. und Papst Innozenz IV. hervor, vgl. dazu Kempf, Friedrich: Die Absetzung Friedrichs II. im Lichte der Kanonistik. In: Probleme um Friedrich II. Hg. von J. Fleckenstein. VuF 16. Stuttgart 1974, S. 345-360.

14 Zum genauen Wortlaut der Absetzungsurkunde siehe RTA ÄR III, Nr. 204, S. 255-260.

15 Im Wesentlichen werden die Anklagepunkte unter sechs Gesichtspunkten zusammengefasst: 1. Wenzels Unvermögen, die Schismafrage zu lösen, 2. Die Erteilung der Herzogswürde an die Mailänder Visconti ohne die ausdrückliche Zustimmung der Kurfürsten; 3. Den Verlust der Reichsherrschaft über die Städte am westlichen Rand des Reiches - d.h. vor allem auf die Übertragung Genuas an Frankreich, das als territorialer Konkurrent galt, 4. Die Erteilung von Blankourkunden mit königlichem Siegel, was allerdings eine verbreitete Rechtspraxis im ausgehenden 14. Jahrhundert war; 5. Die Schuld am Ausbruch zahlreicher, unspezifischer Konflikte im Reich; 6. Der Nachweis, dass Wenzel wie ein Tyrann gehandelt hat, da er sich mit der Hinrichtung von Klerikern Rechte angemasst hat, die eigentlich der Kirche zustehen. 
Papst Bonifaz IX. gedacht war, der sich zu diesem Zeitpunkt noch gegen das Ansinnen der Kurfürsten stellte. ${ }^{16}$

Der politische Erfolg, den die Kurfürsten mit der Absetzung verbuchen konnten, blieb auch in der Historiographie nicht folgenlos. Hier galt die Urkunde lange Zeit als wichtigster Beleg für die Unumgänglichkeit von Wenzels Absetzung. Vergessen ging dabei nicht nur der Entstehungsprozess des Dokumentes, der schließlich in die sechs Anklagepunkte des Depositionsbriefes mündete, sondern auch der Umstand, dass die vorgebrachten Gravamina von Wenzels Gegnern in Reich und Böhmen zum Zeitpunkt der Verschriftlichung bekannt waren; Seit mindestens 1397 waren sie in beinahe unveränderter Abfolge in mehreren Beschwerdebriefen verfeinert worden. ${ }^{17}$ Julius Weizäckers Entscheidung, die Absetzungsurkunde Wenzels in den letzten Teil des dritten Bandes seiner Reichstagsakten zu setzen, gab der Urkunde zusätzliche Prominenz. Sie wurde auch deshalb zur Zäsur, weil sie Weizsäcker - als Original und in Kopialüberlieferung in zahlreichen Archiven zwischen München und Paris aufspürte und somit auch auf die geographische Breitenwirkung des kurfürstlichen Vorstoßes hinwies. ${ }^{18}$ In der deutschen Historiographie überstrahlten die Folgen des kurfürstlichen Akts von Oberlahnstein fortan jede Beurteilung von Wenzels Herrschaft; Theodor Lindner ging sogar so weit, seine wegweisende zweibändige Geschichte zu Wenzels Reichsherrschaft an dieser Stelle abbrechen zu lassen, auch wenn Wenzel als böhmischer König und Kopf der Luxemburger Dynastie bis zu seinem Tode 1419 auf Reichsebene präsent blieb. Erst Petra Roschek, die sich dem Konstruktcharakter der schwarzen Legende Wenzels IV. widmete, hat auch auf jenen, nicht unwesentlichen Anteil verwiesen, den die vorwiegend städtische Chronistik an der Entstehung und Weiterentwicklung des Narrativs von Wenzel als einem „unfähigen“ und „überflüssigen“ König hatte. ${ }^{19}$ Zudem gibt es eine wirkungsvolle Schnittstelle zwischen beiden Textsorten - nämlich die verhältnismäßig häufige Erwähnung der Urkunde in einigen zeitgenössischen Chroniken; Augsburger und Kölner Historiographen des 15. Jahrhunderts bezogen sich direkt auf Textbausteine, desgleichen Chronisten aus

16 Da er seine Meinung zur Tat der Kurfürsten jedoch änderte, musste er seinen Stimmungsumschwung mit der Fiktion unterlegen, sie hätten auf seine Veranlassung hin gehandelt, vgl. RTA ÄR IV. Hg. von J. Weizsäcker. Gotha 1882, Nr. 104, 392.

17 Die Absetzungsurkunde folgte einem Kanon von Gravamina, welcher sich beinahe wortwörtlich an zwei vorangegangenen Schreiben anlehnt; der Klageschrift, welche die Kurfürsten dem König am 23. Dezember 1397 zustellen liessen (RTA ÄR III, Nr. 9, 22-23) und einem älteren Brief der Böhmischen Herren, mit welchem sie 1395 versucht haben, dem König weitgehende rechtliche Zugeständnisse abzupressen, vgl. Hübner, Klara: Mord und Rumford. Politische Propaganda und die Anfänge der Schwarzen Legende König Wenzels IV. In: Reformverlierer 1000-1800. Zum Umgang mit Niederlagen in der europäischen Vormoderne. Hg. von A. Bihrer - D. Schiersner. ZHF, Beiheft 53. Berlin 2016, S. 78-79.

18 Weizsäcker fand Spuren der Urkunde in den Archiven von München, Düsseldorf, Berlin, Luzern, Köln, Memmingen (Sammlung des Anreas von Regensburg), Mainz-Aschaffenburg, Wolfenbüttel, Weimar, der Pariser Nationalbibliothek, der Stiftsbibliothek von Zwettl, Karlsruhe oder Nürnberg. Was den Zeithorizont der Überlieferung angeht, so umfasst er alle Verschriftlichungsphasen zwischen 1400 und der frühen Neuzeit, vgl. RTA ÄR III, Nr. 204, S. 254-255.

19 Roschek, Petra: König Wenzel IV. Opfer einer Schwarzen Legende und ihrer Strahlkraft. In: Regionen Europas - Europa der Regionen. Festschrift für Kurt-Ulrich Jäschke zum 65. Geburtstag. Hg. von P. Thorau - S. Penth - R. Fuchs. Köln 2003, S. 207-229. 
Limburg, Magdeburg, Mainz, Nürnberg, Wien, Straßburg oder Bern. $\cdot{ }^{20}$ Allerdings wurde bisher unterlassen, direkte Textbezüge zwischen den besagten Chroniken nachzuweisen, oder etwa die bevorzugte Verbreitung bestimmter Textpassagen auf persönliche Kontakte unter den Verfassern zurückzuführen. Gleiches gilt auch für den Beizug anderer, ergänzender Informationen, oder die Frage, zu welchem Zeitpunkt der Bezug zu den Fakten aus Wenzels Zeit verloren ging und die Einflüsse aus der Verschriftlichungszeit zur eigentlichen Interpretationsschablone des dargestellten Geschehens wurden.

Als unbestritten gilt, dass auch zeitnahe Niederschriften historischer Tatsachen nicht das Faktische in den Vordergrund stellen müssen. Die Chronistik ist hierfür ein Paradebeispiel: Fernab der Genre- und Normvorstellungen, die Chroniken zweifelsohne prägen, blieben sie stets eine individuelle, zweckgerichtete Interpretation der Geschehnisse, die sich stark an spezifischen, oft lokalen Erzähltraditionen orientierte. ${ }^{21}$ Genauso vielfältig - und heute teilweise unerschliessbar - war auch das Quellenmaterial, von welchem die Chronisten ausgingen. Schriftliches wie Rechtsdokumente, Stadtbücher, ältere Chroniken, Briefe und Gesandtschaftsberichte, Pamphlete oder Flugblätter gehörten genauso ins Repertoire, wie orale Informationen von unterschiedlicher Provenienz und Glaubwürdigkeit - im besten Fall mündliche Berichte von vertrauenswürdigen Akteuren, im Ungünstigsten ephemere Quellen, wie etwa das städtische geschrey, Spottgedichte und Lieder. Auf diese Gemengelage wurde nun der individuelle Filter der politischen und lebensweltlichen Vorstellungen des - häufig geistlichen - Chronisten und/oder seiner patrizischen oder adeligen Auftraggeber gelegt, welcher letztlich für die Tendenz des Werks, d.h. das portierte Geschichtsbild, entscheidend war. Damit galt das Verhältnis zwischen historischen Ereignissen und ihrer Widergabe oft weitaus weniger rational, als uns deren Darstellung oftmals vermuten lässt. Schon der Epistemologe Ludwig Fleck hat darauf hingewiesen, dass irrationale Phänomene bei der schriftlichen Rezeption historischer Fakten häufig eine wichtigere Rolle spielten, als ihnen Historiker gemeinhin zugestehen wollen ${ }^{22}$. Damit meinte er nicht nur die Verzerrung historischer Ereignisse aufgrund der Beschränkung der menschlichen Wahrnehmung, sondern all jene, die zu einer einseitigen Sicht auf das Geschehene führen, und damit auch deren historiographische Reproduktion befördern. Die Einseitigkeit konnte unverfänglicher Natur sein, etwa wenn der Schreiber den Zugang zu den kulturellen Codes der beschriebenen Zeit verloren hatte, nicht am Geschehen interessiert war oder wenn er isoliert und nur mit beschränktem Quellenzugang gearbeitet hat. Doch sie konnte auch das Ergebnis gezielter Manipulation sein, die von einer bewusst

20 Roschek verweist auf zahlreiche zweitgenössiche Chroniken und Chronisten, welche die besagten Ereignisse um Wenzels Absetzung darstellen, unter anderem, Johan von Posilge $(\uparrow 1404 / 5)$, Jakob Twinger von Königshofen (1346-1420), Gobelinus Person (1358-1421), Ludolf von Sagan (1353-1422), Edmund de Dynter $(\dagger 1448)$, Andreas von Regensburg ( $\uparrow 1438)$, Hermann Korner (1365-1438), siehe Roschek, P.: König Wenzel IV., S. 212, Anm. 23.

21 Über die Bedeutung und die Mechanismen von historischem Erzählen im Allgemeinen siehe Rüsen, Jörn: Zeit und Sinn. Strategien historischen Denkens. Frankfurt am Main 2012; darin insbesondere das Kap. „Die vier Typen des historischen Erzählens“, S. 153-230; White, Hayden: The value of narrativity in the representation of reality. Critical Inquiry 7/1, 1980, S. 5-27.

22 Vgl. Fleck, Ludwig: Entstehung und Entwicklung einer wissenschaftlichen Tatsache. Einführung in die Lehre vom Denkstil und Denkkollektiv. Frankfurt am Main 20129. 
gewählten Einseitigkeit der Quellen über die Strahlkraft von übernommenen Meinungen oder gar auf falschen Belegen aufbauenden Doktrinen bis hin zur Durchsetzung bestimmter von Wissenschaftskoryphäen geprägten Diskursen reichen konnte ${ }^{23}$. Letzteres stellt beim Bespiel Wenzel das größte Problem dar; Verfolgt man nämlich die kontinuierliche Entwicklung der Motive in der deutschsprachigen Chronistik der ersten Jahrzehnte nach seiner Absetzung, so kann man daran nicht nur den Anfang jenes Prozess beobachten, welcher letztlich zur einseitigen Sicht späterer Historiographen führt, sondern auch die Verwandlung der ohnehin bereits tendenziösen Argumente des Absetzungsdokumentes in geradezu fantastische Narrative.

Doch greifen wir nicht vor; bei der ersten Generation von Chronisten, die nach der Absetzung Wenzels geschrieben haben, wird die gesellschaftliche Polarisierung, die das Ereignis hervorgerufen hatte, am stärksten herausgestrichen. Aufgrund der zeitlichen Nähe hatten sie auch den direktesten Zugriff auf unmittelbare Informationen, die angesichts der beidseitigen konfessionellen Propaganda der Hussitischen Revolution immer stärker in den Hintergrund rückte. ${ }^{24}$ Etwas verfälschend wirkt dabei allerdings, dass in der deutschen Historiographie vor allem jene Stimmen Gehör fanden, die mit dem Schritt der kurfürstlichen Opposition sympathisiert haben. Unter ihnen befand sich etwa der Preuße Johan von Posilge, der spätere Chronist Sigismunds von Luxemburg, Eberhard Windecke oder aber Abt Ludolf von Sagan, welcher zu den schärfsten Kritikern des Königs gehörte. ${ }^{25}$ Im süddeutschen Raum verbreitete sich indes die Straßburger Chronik des Jakob Twinger von Königshofen, die im 15. Jahrhundert im Elsass und einigen Städten der Alten Eidgenossenschaft besonders stark rezipiert wurde und dadurch auch der einseitigen Wahrnehmung der Ereignisse Vorschub leistete. ${ }^{2}$ Während

23 Fleck entwarf die Vorstellung des „Denkkollektivs“, das für ihn „Träger einer geschichtlichen Entwicklung eines Denkgebietes, eines bestimmten Wissensbestandes und Kulturstandes, also eines Denkstils war“. Wissenschaftlergruppen, die die stabilste Form eines Denkkollektiv darstellen, hätten allerdings den Hang, ihre Überzeugungen und Handlungsmuster als selbstverständlich wahrzunehmen und damit Systeme zu schaffen, in welche sich neue Ideen oder Perspektiven nur schwer integrieren liessen; vgl. ebd., S. 141.

24 Eine Ahnung vom ungeheueren Umfang der antihusstischen Propaganda in den Jahren zwischen 1420 und 1436 vermittelt die von Pavel Soukup angeregte, interaktive Sammlung „Repertorium operum antihussiticorum“, die bis dato nur teilweise aufgearbeitet worden ist [http://www.antihus.eu, 28. 12. 2018].

$25 \mathrm{Zu}$ Johann von Posilge vgl. Johans von Posilge, Officials von Pomesanien, Chronik des Landes Preussen zugleich mit den auf Preussen bezüglichen Abschnitten aus der Chronik Detmars von Lübeck. In: Scriptores rerum Prussicarum III. Hg. von T. Hirsch - M. Töppen - E. Strehlke. Leipzig 1866, S. 13-57, 79-397; in Eberhard Windeckes Äusserungen spielt Wenzel IV. keine Rolle, siehe Schwob, Ute Monika: Ideologischer und militärischer Kampf gegen die Hussiten. Oswald von Wolkenstein und Eberhard Windecke als Zeitzeugen. In: Deutsche Literatur des Mittelalters in und über Böhmen II. Hg. von V. Bok - H.-J. Behr. Schriften zur Mediävistik 2. Hamburg 2004, S. 301-318; Abt Ludolf von Sagan verfasste in seinem tractatus de longaevo schismate eine der wirkmächtigsten Kritiken an Wenzel IV., den er zum Hauptverantwortlichen für den Aufstieg des Hussitismus erhob; vgl. Ludolf von Sagan. Tractatus de longevo schismate. Hg. von J. Loserth. Archiv für österreichische Geschichte 60, 1880, S. 345-561. Mehr dazu Machilek, Franz: Das Grosse Abendländische Schisma in der Sicht des Ludolf von Sagan. In: Das Konstanzer Konzil. Hg. von R. Bäumer. Wege der Forschung 415. Darmstadt 1977, S. 37-95.

26 Der Berner Chronist Konrad Justinger, der seine Berner Chronik in den 1420er Jahren verfasst, bezieht sich direkt auf die Strassburger Chronik Jakob Twingers von Königshofen; Strahm, Hans: Der Chronist Conrad Justinger und seine Berner Chronik von 1420. Bern 1978. 
Königshofen seine Informationen über die auf Böhmen bezogenen Anklagepunkte aus zweiter Hand bezog, hatten Johan von Posilge, allerdings auch Ludolf von Sagan einen direkteren Zugang. Beide hatten in den 1370er bzw. 1380er Jahren in Prag studiert und verfügten immer noch über gute Kontakte in den böhmischen Raum. ${ }^{27}$ Auch Windecke hatte sich hier 1395 als junger Kaufmann aufgehalten. In den Folgejahren blieb er als Gefolgsmann in Diensten des Herzogs Stephan von Bayern-Landshut mit dem böhmisch-bayrischen Raum verbunden. Er war es denn auch, der dem Geschehen von Oberlahnstein unter den Genannten physisch am Nächsten kam; ${ }^{28}$ eines der am 20. August 1400 verfassten Augenzeugenprotokolle, die für Rechtsgültigkeit der Absetzung notwendig waren, stammten von seiner Hand. ${ }^{29}$ Im Gegensatz zu den übrigen, äußerte sich Windecke weder im Protokoll noch in seinen späteren Werken abschätzig über Wenzel IV., sondern streicht die politische Dimension der Absetzung und ihre Folgen heraus. Unter den Chronisten, deren Werke noch zu Lebzeiten Wenzels oder kurz danach verfasst wurden, bildet sein analytischer Blick nicht nur eine inhaltliche Ausnahme; er ist der einzige Nicht-Kleriker, der sich zu den Erignissen chronikalisch äußert.

Dass die schärfere Gangart gegen Wenzel IV. vor allem Sache von Kirchenleuten war, zeigt sich an den allerfrühesten Belegen für die Verwertung der Urkunden-Gravamina. Nicht zufällig tauchen diese in den Einflussgebieten der geistlichen Kurfürsten auf, wo der Akt von Oberlahnstein auch wegen der politischen Nähe zu Wenzels Nachfolger, Ruprecht von der Pfalz, in den ersten Jahren einen hohen Identifikationswert besaß. Der Mainzer Domherr Johannes Kungstein, dessen Eintrag im Chronicon Moguntinum im Jahr 1401 entstanden sein muss, oder die 1402 vollendete Limburger Chronik des Tileman Ehlen von Wolfenhagen, gehören zu den ersten, die ihre Argumentation gegen Wenzel auf den Gravamina aus der Urkunde aufbauen. ${ }^{30}$ Wolfenhagen erörtert insbesondere den kirchenrechtlich relevanten Vorwurf, Wenzel sei ehrlos, da er sich mit Gesellen von moralisch zweifelhaftem Ruf umgeben würde. Ein wonderlicher - sprich: unwürdiger - König sei er, der wie im Übrigen auch im sechsten Anklagepunkt gezeigt wurde, einen Hang zum Verbrechen habe. ${ }^{31}$ Kungstein bezieht klar Partei für Ruprecht, indem er den politischen Coup der Kurfürsten als einstimmige Wahl darstellt. ${ }^{32}$ Er lässt

27 Hübner, K.: Mord, S. 78.

28 Wyss, Arthur: Windeck, Eberhard. In: Allgemeine Deutsche Biographie. Bd. 43. Leipzig 1898, S. 381-387.

29 Vgl. RTA ÄR III, Nr. 214, S. 273.

30 Johannes Kungstein, Chronicon Moguntinum. In: Die Chroniken der deutschen Städte vom 14. bis ins 16. Jahrhundert XVIII. Die Chroniken der mittelrheinischen Städte. Mainz. II. Hg. von C. Hegel. Leipzig 1882, S. 147-250, hier S. 236-239; Tileman Ehlen von Wolfenhagen, Limburger Chronik. In: Monumenta Germaniae Historica (= MGH). Deutsche Chroniken IV-1. Hg. von A. Wyss. Hannover 1883, S. 71-91.

31 Letzteres leitet Wolfenhagen aus den Nachrichten über Wenzels seltsamen Lebenswandel ab: Unde Wenzelaus Romescher konig unde konig zu Behemen der lachte sich wonderlichen an; want he des nachtes reit zu Prage in di stat alleine, selpander oder selbdritten unde also, unde slug sich mit den buben als ein ander bube. Unde dreip he also vil ungelimpes unde buberie, daz alle di wernt in bestont zu hassen, daz ouch hernach geschreben stat, wi he von der Romeschen riche vurstossen wart; siehe Tileman Ehlen von Wolfenhagen, Limburger Chronik, S. 72.

32 Zum Ausmass der politischen Intrigen auf der Seite der geistlichen Kurfürsten siehe Die Vorgeschichte der Thronrevolution von 1400 in officiöser Darstellung. Aus dem Nachlasse Julius Weizsäcker's. Deutsche Zeitschrift für Geschichtswissenschaft 7, 1892, S. 142-147. 
nichts unversucht, um Wenzel in ein zweifelhaftes Licht zu stellen; sein Verweis auf elf Gravamina - von denen bereits eines ausgereicht hätte, um Wenzel abzusetzen - zeigt, dass ihm wohl der kurfürstliche Beschwerdebrief von 1397 zur Verfügung stand, welcher deutlich detaillierter ist als das Absetzungsdekret. ${ }^{33}$ Er zitiert allerdings nur jene Gravamina, die auch in der Absetzungsurkunde erscheinen: Wenzel habe Genua an die Mailänder veräußert, denen er zusätzlich die Herzogswürde verliehen hätte, sich mit Heiden gegen die Christenheit verbündet, Doktoren der Theologie umgebracht und überhaupt unzählige Übeltaten begangen - und all das, ohne das nunmehr 23 Jahre andauernde Schisma zu lösen. ${ }^{34}$

Einen ähnlichen Duktus hat auch die 1416 abgeschlossene Strassburger Chronik des Kanonikers Jakob Twinger von Königshofen, dem ebenfalls die Absetzungsurkunde vorgelegen haben muss. ${ }^{35}$ Nicht nur räumt er den Garvamina deutlich mehr Platz ein; sondern macht sie zum Kulminationspunkt der Meistererzählung von Wenzel als böser here, welcher von ihm zwischen einem Tyrannen und dem alttestamentarischen Jerobeam verortet wird. ${ }^{36}$ Auch Jakob Twinger von Königshofens argumentative Engführung dient letztlich der Rechtfertigung von Wenzels Absetzung, was nicht nur eine Diskussion der einzelnen Punkte des Absetzungsdekrets überflüssig macht, sondern mitunter darauf verweist, dass dieser Chronikabschnitt bereits unter dem Einfluss der Ereignisse am Konstanzer Konzils stand. Entsprechend präsent sind in seiner Argumentation deshalb auch die Verweise auf Motive, die mit der Charakterisierung von Ketzern und Randständigen zusammenhängen. Dazu gehört etwa das Propagandamotiv, Wenzel hätte die Reliquiensammlung seines Vaters aus niederen Beweggründen verkauft oder seine angebliche Freundschaft zu einem Henker. ${ }^{37}$ Hinzu kommt Wenzels angebliche feindselige Haltung gegenüber dem Reich und seinen Institutionen, die sich in Jakob Twinger von Königshofens Beschreibung der Mordnacht von Karlstein (1397) ausdrückt, einer innerböhmischen Hofintrige,

$33[. .$.$] habitis tamen prius omnibus sollemnitatibus privationis de rege Wentzesslao; rege Bohemiae antea Romanorum$ sed nunc privato. In eadem privatione principes electores undecim articulos objectivos contra eundem privatum habuerunt, quorum unusquisque ad depositionem regni Romanorum sufficiebat; siehe Johannes Kungstein, Chronicon Moguntinum, S. 239.

34 Der Vorwurf, Genua vom Reich entfremdet zu haben, kommt einzig im Beschwerdebrief vom 23. Dezember 1397 vor: Quorum unus fuit articulus, quod civitatem Januensem ab imperio alienavit, dominum Mediolanensem in ducem creavit, cum infeidelibus latenter contre Christianos tenuit, doctores sacre theologie occidit, innumera mala, que omnia scribere tedosium foret, peregit; siehe ebd.

35 Jakob Twinger von Königshofen, Die älteste Teutsche so wol Allgemeine, als insbesondere Elsässische und Strassburgische Chronicke. In: Die Chroniken der deutschen Städte vom 14. bis ins 16. Jahrhundert VIII. Die Chroniken der oberrheinischen Städte. Strassburg. I. Hg. von C. Hegel. Leipzig 1870, S. 494.

36 Das Jerobeam-Motiv (missratener Sohn des weisen Königs Salomons) hat in der tschechischen Chronistik eine längere Tradition. Bereits Peter von Zittau hat es benutzt, um einen Vergleich zwischen der Herrschaft der Premyslidenkönige Wenzel II. und Wenzel III. zu ziehen. Seine Hauptkritik galt vor allem dem Einfluss „fremder“ Eliten, die letzterer gegen die böhmischen Herren auspielen würde. Dazu mehr Novotný, Robert: Ráj milců? Nižši šlechta na dvore Václava IV. In: Dvory a rezidence ve středověku II. Skladba a kultura dvorské společnosti. Hg. von D. Dvořáčková-Malá - J. Zelenka. Mediaevalia Historica Bohemica, suppl. 2. Praha 2008. S. 215-229.

$37 \mathrm{Zu}$ Wenzels ketzerischem Mutwillen siehe etwa: [...] Das heiltum daz sin vatter mit grossem ernste von ferren landen broht und in golt und silber mit grosser gezierde gemacht, daz zerbrach er und nam daz golt und silber, wiewol er sin nüt bedürfte; siehe Jakob Twinger von Königshofen, Strassburgische Chronicke, S. 494. 
über die im Reich nur wenig bekannt war. In seiner Version fallen nicht vier Kronräte Wenzels einer auf Korruptionsvorwürfen beruhenden Palastintrige zum Opfer, sondern weil sie den König bitten wollten, sich mit den Kurfürsten am Rhein zu treffen. ${ }^{38}$ Dieser angeblich von Wenzel abgesegnete Mord stellte ihn in Königshofens Auslegung nicht nur außerhalb der Gesellschaft, sondern auch außerhalb der Reichsinteressen. Dass diese Sicht auch im Elsass und der Eidgenossenschaft große Verbreitung fand, war nicht nur das Ergebnis einer durch die Obödienzfrage polarisierten Haltung der Städte, die sich auch in ihrer Haltung gegenüber dem Reichsoberhaupt ausdrückte. Weitaus bedeutender war die grosse, spätmittelalterliche Rezeption von Königshofes Chronik in diesem Raum. Auch wenn der König dabei eine chronikalische Randerscheinung bleibt, ist doch der Grundtenor seiner Beschreibung verhältnismäßig einheitlich. Exemplarisch trifft dies für die 1420 und 1430 entstandenen Berner Chronik des Konrad Justinger zu, welcher den Straßburger Jakob Twinger von Königshofen sehr wahrscheinlich persönlich kannte. Das Absetzungsdekret lag Justinger nicht vor, dafür Königshofens Weltchronik. Seinen Wenzel nennt er, analog dazu, valsch und böse; die Deposition durch die Kurfürsten sei rechtens gewesen, da dieser dem rich nie gut getet hätte. ${ }^{39}$

Von den Chronisten, die Zugriff auf die Urkunde hatten und zu Lebzeiten Wenzels schrieben, wurde sie ausschließlich zur Rechtfertigung seiner Absetzung benutzt. Diese Einseitigkeit liegt auch darin begründet, dass sich im Reich aus dem besagten Zeitraum keine chronikalischen Gegenstimmen erhalten haben. ${ }^{40}$ Dafür war es nicht notwendig, den Hintergrund der einzelnen Gravamina genau zu kennen. In der Chronistik aus den Gebieten der geistlichen Kurfürsten ging es vor allem darum, Wenzel als moralisch verwerflichen, im kirchenrechtlichen Sinne ,skandalösen“ König darzustellen. ${ }^{41}$ Alleinstellungspotenzial entwickelte in ihrer Argumentation bloss der sechste Vorwurf, wonach Wenzel mit syns selbes hand bidderbe prelaten pfaffen und geistliche lude und auch viele Laien ermordet, ertränkt und mit Fackeln verbrannt habe. Er ist neben der ebenfalls gerne zitierten Anschuldigung, Wenzel habe nichts unternommen, um das Schisma zu lösen,

38 Ebd., S. 494. Die beste Rekonstruktion der Mordnacht von Karlstein bietet immer noch: Štěpán, Václav: Vražda čty̌r členů králouské rady na Karlštejne roku 1397. Český časopis historický 92/1, 1994, S. 24-44.

39 Justingers Eintrag zu Wenzel ist konzis, spielt aber ebenfalls auf die vermeintliche Ehrlosigkeit Wenzels an; Do man zalte von gots geburt MCCCC jar, küng wentzlaw von beheim, der meng jar römscher küng gewesen waz, wart von dem rich entsetzet und von gemeinen kurfürsten abgesetzt; won der anfang valschs und böse waz, als er gesetztet wart, daz mittel böser, won er dem rich nie gut getet, daz ende aller böst, wan er mit schaden und uneren abgesetzet wart. Vgl. Die Berner-Chronik des Conrad Justinger. Hg. von G. Studer. Bern 1871, S. 187.

40 Einzig in der hussitischen Chronistik wird Wenzel positiv dargestellt. Da diese infolge der politischen und konfessionellen Isolation der Böhmischen Länder nach den Hussitenkriegen keine Rezeption von ausserhalb erfährt, wird dieses Narrativ bis zu seiner Entdeckung und Instrumentalisierung durch die Nationalerneuerer im 19. Jahrhundert auch nicht weiterentwickelt; mehr dazu bei: Bartoš, F. M.: Husũv král, S. 13-14, Graus, František: A propos de la „réligion royale“ au bas Moyen Age. Venceslas IV et la mystique royale dans la Bohême hussite. In: Histoire sociale, sensibilités collectives et mentalités. Hg. von P. Joutard. Paris 1985, S. 507-516; ders.: Die Herrschersagen des Mittelalters als Geschichtsquelle. In: František Graus Ausgewählte Aufsätze 1959-1989. Hg. von H.-J. Gilomen - P. Moraw - R. C. Schwinges. VuF 55. Stuttgart 2002, S. 3-27.

41 Eine Studie, welche der Frage nachgeht, welche Bedeutung die strafrechtliche Kategorie des scandalum bei der Absetzung spätmittelalterlicher Könige hatte, wird gegenwärtig für die Zeitschrift für historische Forschung vorbereitet. 
der einzige mit einem realen politischen Hintergrund. Gleichzeitig lässt er erkennen, wie sich die fama des Königs in den Jahren vor seiner Absetzung kontinuierlich verschlechterte. Das Ereignis, auf welches sich der sechste Punkt bezog, hatte sich 1393, sieben Jahre zuvor im Verließ des Königlichen Burgvogtes auf der Prager Burg abgespielt. In der Nacht vom 19. auf den 20. März war hier der Prager Generalvikar Johann von Pomuk, die rechte Hand des damaligen Prager Erzbischofs Johannes von Jentzenstein unter der Folter verstorben - sein Körper wurde anschließend auf Geheiß Wenzels in die Moldau geworfen. ${ }^{42}$ Der Hintergrund der Tötung, für welche der König mitverantwortlich war, stand eine erbitterte machtpolitische Fehde zwischen Erzbischof und König, die seit den 1380er Jahren schwelte. Streitpunkt waren nicht nur Kirchfragen, in denen Jentzenstein durchaus orthodoxe Standhaftigkeit bewies, sondern vor allem die Fiskalpolik der Kirche, von deren Einschränkung sich Wenzel finanzielle Vorteile versprach.

Die Situation eskalierte, nachdem Wenzel die Absicht geäußert hatte, das Benediktinerkloster von Kladruby (Kladrau), welches bislang zum Prager Erzbistums gehört hatte, zum eigenständigen Bistum von des Königs Gnaden zu erheben und damit Jentzensteins territoriale Herrschaftsbasis um ein Drittel zu schmälern. ${ }^{43}$ Dies konnte der Erzbischof mit einem juristischen Handstreich zwar vereiteln. Seine engsten Hofleute, unter ihnen Johann von Pomuk, wurden allerdings von Wenzel gefangengesetzt und gefoltert, um sehr wahrscheinlich mehr über die mittelfristigen Absichten jener Hintermänner zu erfahren, die den Erzbischof bei seiner Tat unterstützt hatten. ${ }^{44}$ Nach Pomuks Tod, welcher zu den gröbsten politischen Misstritten des Königs zählt, verfasste Jentzenstein eine pamphletartige Anklageschrift, die Acta in curia romana, welche über Kirchenmedien rasch unter den politischen Gegner des Königs Verbreitung fand und später auszugsweise ins Absetzungsdekret übernommen wurde. ${ }^{45}$

Während die ersten fünf Gravamina des Dekrets immer noch die politische Motivation der kurfürstlichen Opposition durchblicken lassen, zielte der Vorwurf, eigenhändig gemordet zu haben, auf die persönliche Integrität des Königs ab. Mindestens seit dem Investiturstreit galten Angriffe auf die Würde von Königen als beliebte Mittel der jeweiligen politischen Opposition ${ }^{46}$. Am Ende des 14. Jahrhunderts hatte sich daher auch

42 Das Wissen um die Hintergründe der Causa Pomuk ist aufgrund seiner Bedeutung als Nationalheiliger in der tschechischen deutlich grösser als in der deutschen Literatur, vgl. dazu die jüngeren Arbeiten von: Polc, Jaroslav V.: Svatý Jan Nepomucký. Praha 1993; Vlnas, Vít: Jan Nepomucký, česká legenda, Praha 1993; ders.: Svatý Jan Nepomucký, světec baroka aneb druhý život Johánka z Pomuku. In: Pět hvězd nad českým královstvím. Svatý Jan Nepomucký a katolická reformace. Barokní jezuitské Klatovy 2013. Hg. von V. Chroust - Z. Bursíková - K. Viták. Klatovy 2013, S. 49-78. Die westliche Forschung bezieht sich indes immer noch auf die schon ältere Studie aus der Feder eines Engländers; Weltsch, Ruben Ernest: Archbishop John of Jenstein (1348-1400). Papalism, Humanism and Reform in Pre-Hussite Prague. Studies in European History 8. Den Haag 1968; Hübner, K.: Mord, S. 70-75.

43 Weltsch, R. E.: Archbishop John of Jenstein, S. 68.

44 Dies ist bis heute die wahrscheinlichste Erklärung für die besagten Ereignisse, die sich aufgrund mangelnder Quellen nur teilweise rekonstruieren lassen, vgl. Lindner, T.: Geschichte, Bd. 2, S. 184-185.

45 Ediert von Paul DeVooght: Jean de Pomuk. Le mythe de Jean Népomucène. In: Hussiana. Bibliothèque de la revue d'histoire ecclésiastique 35. Louvain 1960, S. 400-421.

46 Vgl. etwa Herde, Peter: Ein Pamphlet der päpstlichen Kurie gegen Kaiser Friedrich II. von 1245/46 („Eger cui lenia“). Deutsches Archiv für Erforschung des Mittelalters 23, 1967, S. 468-538, bzw. Anm. 13. 
die Palette der dabei gebräuchlichen politischen Narrative deutlich ausdifferenziert. ${ }^{47}$ Die zumeist klerikalen Chronisten, die in der Zeit bis 1420 schrieben, brauchten daher nicht lange, um Wenzel den Anstrich eines Alter Nero zu verpassen. ${ }^{48}$ Bereits 1401 wusste Johannes Kungstein zu berichten, dass Wenzel, den Übermittler der kurfürstlichen Ladung nach Oberlahnstein, in grosser Wut ertränken liess. ${ }^{49}$ Laut Tileman Ehlen von Wolfenhagen lebte Wenzel seinen Hang zum Verbrechen aus, indem er wie Kaiser Nero bei Nacht mit üblen Gesellen durch Prag geritten sei und sich mit den buben als ein ander bube geschlagen hätte. Einen direkten Verweis auf die antike Nero-Vita Suetons macht auch die von Jakob Twinger von Königshofen tradierte Episode, wonach Wenzel den Freiheitenbrief seines Vaters für die Stadt Prag eigenhändig zerrissen habe. ${ }^{50}$

Erst in den Chroniken, die zwischen Konstanzer Konzil und dem Abschluss der Hussitischen Revolution entstanden, also etwa im Zeitraum zwischen 1416 und 1436, verschmolz das Motiv des unfähigen und moralisch unwürdigen König Wenzel aus der Absetzungsurkunde mit dem zweiten strafrechtlichen Indikator für schlechte fama - dem Vorwurf der Ketzerei. Entsprechend tauchen dessen Narrative in der katholischen Pamphletliteratur auf, etwa bei Johan von Posilge, der als Chronist im Deutschordensland tätig war. Für seine um 1420 abgeschlossene Preußische Chronik entlehnt er daraus etwa das Motiv eines hussitischen Wenzels, welcher in den Werkstätten der Prager Steinmetze eigenhändig Heiligenfiguren zerstört hätte. Eine ähnliche Beschreibung heidnischen Treibens taucht im besagten Zeitraum auch in der Polemik zwischen Polnischem König und deutschem Orden auf. ${ }^{51}$

Das düsterste Bild des Königs zeichnet allerdings der Dominikaner Hermann Korner. In seiner 1435 in Magdeburg abgeschlossenen Chronica Novella, die wohl gänzlich unter dem Einfluss der Hussitenkriege entstanden war, verdichtet er Gravamina aus dem Absetzungsdekret, antike Erzähltraditionen, Polemik aus der katholischen Pamphletliteratur sowie mündlich tradierte Gerüchte über die Grausamkeiten der Hussiten, zu einem düstersten Narrativ. ${ }^{52}$ Sein Wenzel ist nunmehr ein teuflischer Trunkenbold und mutwillig handelnder Wahnsinniger, der Priester und Laien mordet und auch die von seinem Vater geliebte und gepflegte Universität Prag in den Untergang führt. Korner schmückt das Märchenmotiv des mit dem König befreundeten Henkers zusätzlich aus,

47 Petr Čornej widmet sich auf tschechischer Seite seit über 30 Jahren dem Herkommen der zahlreichen mit Wenzel IV. assoziierten Erzählmotive; paradigmatisch dazu ders.: Václav IV. v proměnách času. Př́spěvek k české pověsti královské. Česká literatura 33/5, 1985, S. 408-424; in konzentrierter Form, allerdings ohne kritischen Apparat vgl. ders.: Dvojí tvář Václava IV. In: ders.: Tajemství českých kronik. Cesty ke kořenům husitské tradice. Praha 2003², S. 67-115, 390-401.

48 Zu Gleichsetzung Wenzels mit Nero siehe ebd., S. 80-85.

49 Johannes Kungstein, Chronicon Moguntinum, S. 238.

50 Jakob Twinger von Königshofen, Strassburgische Chronik, S. 494.

51 Johans von Posilge Chronik des Landes Preussen, S. 200; zur Benutzung desselben Motivs in der anti-polnischen Polemik am Konstanzer Konzil siehe Bar, Přemysl: Omnes Poloni essent heretici. Kauza Jana Falkenberga a diskuze o pojmu „hereze“ na kostnickém koncilu. In: Cesta k rozmanitosti aneb Kavárenský povaleč digitálním historikem středověku. Sborník příspěvků k životnímu jubileu PhDr. Zdenka Uhlíře. Hg. von R. Modráková - T. Klimek. Praha 2016, S. 56-64. 
indem er ihn den Namen Hetzel gibt. ${ }^{53}$ Doch damit nicht genug; Korner weiss auch zu berichten, dass Wenzel sogar die eigene Gemahlin gezwungen habe, sich in öffentlichen Bordellen zu prostituieren. ${ }^{54}$

Am Ende der Hussitenkriege haben sich die negativen Chroniknarrative also nicht nur vervielfacht und ausdifferenziert, sondern auch definitiv von den Ereignissen gelöst. Die Frage der Quellen war in den Hintergrund gerückt, die kulturellen Codes waren oftmals verloren bereits gegangen. Zudem hatten sich auch die politischen Prioritäten verschoben. Ausserhalb der Gebiete, die es unmittelbar betraf, blieb das Wissen um Wenzels Absetzung löchrig. Letzteres gilt etwa für die 1443 abgeschlossene Augsburger Chronik des Ratsherren Ehrhard Wahraus, welcher - trotz der geographischen Nähe zum böhmischen Geschehen - vor allem Lokales zu berichten wusste. Von den Gravamina scheint er nie gehört zu haben. Von Wenzel wusste er nur noch, dass er in Prag gelebt, den hussenglauben eingeführt und eine bayrische Ehefrau gehabt hatte. ${ }^{55}$

Was lässt sich also zum Schluss festhalten? Vielleicht der Umstand, dass selbst grosse politische Ereignisse auch im Spätmittelalter kurze Halbwertszeiten hatten und vor allem davon abhängig waren, wo sich ein Chronist aufhielt. Vielleicht auch, dass chronikalische Erinnerung nicht zwingend auf Fakten aufbauen musste. Die Gravamina in Wenzels Absetzungsurkunde lösten sich jedenfalls innerhalb von wenigen Jahrzehnen von den Ereignissen und verschmolzen mit älteren, überpersönlichen Narrativen. Im Falle des Aktes von Oberlahnstein reichte dazu eine Generation. Schon um 1450 kannten die Chronisten weder den genauen Ablauf von Wenzels Absetzung, noch die rechtlichen Umstände, die diese begünstigt hatten. Wenzel war zu einem weiteren Beispiel für schlechtes Königtum geworden. Von dieser Verwandlung blieben auch die Fakten hinter dem sechsten Punkt des Absetzungsdekrets nicht verschon. Vierzig Jahre nach der Ermordung des Prager Generalvikars Pomuk hatten sich die Gründe für seine Tötung in ein Erzählmotiv verwandelt, in welchem das bereits erwähnte Nero-Narrativ mit einem, gegen dessen Gemahlin Sophie von Bayern gerichteten Propagandamotiv verschmolzen. Der österreichische Chronist Thomas Ebendorfer, welcher als katholischer Legat am Basler Konzil mit den Verhältnissen im nachhusstischen Böhmen vertraut war, beschrieb Johannes Pomuk in seiner 1454 verfassten Kaiserchronik als den Beichtvater der Königin, den Wenzel deswegen habe ertränken lassen, weil er ihm nicht von ihrer unter der Beichte gestandenen Untreue berichten wollte. ${ }^{56}$

53 Studium Pragense non fovit neque dilexit, sicud pater ipsius fecerat. Multa homicidia in clericis graduatis et non graduatis, in civibus in nobilibus et laycis commisit [...]; siehe Die Chronica Novella des Hermann Korner, Fassung A, S. 72-73.

54 Lictorem nomine Henzel pro compatre habuit. Uxorem propriam ad lupanar publicum prostitutam ire coegit. Hic multociens intoxivatus extitit, sed inde mortuus non fuit (dyabolo forte pro suo instrumento ipsum conservante); siehe Die Chronica Novella des Hermann Korner, Fassung A, S. 73.

$55[\ldots]$ und bey kinig Wencelaus, der ze Prag sass, der den hussengelauben anfieng, und sein fraw was eine von Payern, dau zalt man 1410 jaur [...]; vgl. Chronik des Erhard Wahraus 1126-1445, mit Nachträgen zum Jahr 1462. In: Die Chroniken der deutschen Städte vom 14. bis ins 16. Jahrhundert IV. Die Chroniken der schwäbischen Städte. Augsburg. I. Ed. C. Hegel. Leipzig 1894, S. 199-264, hier S. 228.

56 Confessorem eciam uxoris sue Johannem in theologia magistrum, et quia dixit, hanc dignum regi nomine, qui bene regit et, ut fertur, quia sigillum confessionis violare detrectat, ipsum in Moldauia suffocari precipit; siehe Thomas 
Was von Wenzel übrig bleibt, sind nicht politische Taten oder ein klares Bild seiner Persönlichkeit, sondern ein Dickicht aus Erzählmotiven, an welchen sich frühneuzeitliche und moderne Historiker mit unterschiedlichem Erfolg abgearbeitet haben. Diese Motive, entstanden in einer hoch komplexen, gesellschaftlich wie politisch dynamischen Zeit, können zwar nicht beantworten, ob Wenzel ein schlechter König war. Sie können indes einen Einblick in die Wirkungsweisen und Kommunikationsmuster spätmittelalterlicher politischer Oppositionsgruppen geben, die für deren Erforschung noch aufschlussreich sein wird.

\section{Využití sesazovací listiny Václava IV. v kronikářství říšských měst 15. století}

Václav IV. patří mezi nejkontroverznější krále nejenom českých, ale též německých dějin. Zatímco v české historiografii získal i pozitivní přívlastky - začínaje „Husovým ochráncem“ a „lidovým králem“ konče - v německé historiografii se proslavil především negativně. Od 19. století je zde považován za neschopného krále, tyrana a padoucha, který vážně poškodil politické zájmy říše. Značný vliv na vznik této představy měla listina, na jejímž základě se alianci okolo římských kurfiřtů podařilo sesadit českého krále z římského trůnu. Jednalo se o důmyslně připravený právně-politický dokument, ve kterém se spojovala argumentace a politická síla Václavových protivníků: Jednak šlo o vlivnou skupinu českých pánů, kteří již od jeho prvního zajetí veřejně propagovali celou škálu stížností na krále, jednak o jejich ideové spojence mezi duchovními kurfiřty. Mezi ně patřili především aktéři okolo vlivného mohučského arcibiskupa Jana II., kteří od 80. let 14. století usilovali o krále ze „zemí Římské Říše“. Vysoce inovativní nebyla listina pouze kvůli uvedené shodě mezi Václavovými politickými protivníky za využití kanonistů z řad Heidelberské univerzity, kteří jí zformulovali. Její průraznost souvisela spíš s nárokem kurfiřtů, kteří ze sebe v dokumentu činí ochránce zájmů Říše proti vlivům zlého a neschopného krále. Díky množství zhotovených a rozeslaných opisů se tato představa stala i základem špatného jména krále Václava v historiografickém diskurzu říšských měst v první polovině 15 . století. Zde byla častokrát jediným dokumentem, po kterém kronikáři mohli sáhnout, když se chtěli dozvědět více o králi, kterému byla v dobovém mínění připsána vina za propuknutí husitských válek. Neudiví, že se protiváclavská argumentace $\mathrm{z}$ listiny projevovala nejdříve $\mathrm{v}$ kronikářství měst $\mathrm{v}$ přímém vlivu duchovních kurfiřtů, jako byla třeba Mohuč. Již v roce 1401 zde vznikla kronika kanovníka Jana Kungsteina, který byl stoupencem Ruprechta Falckého. Zatímco se jeho popis Václavových nedostatků vztahuje na politické diskurzy související s jeho sesazením, splývá negativní představa o českém králi pouze o patnáct let později s výčitkou kacířství, o kterém se však v listině ještě nemluví. Kronika Štrasburského písaře Jakuba Twingera z Königshofenu vzniká již pod vlivem událostí na Kostnickém Koncilu, po kterém se v kronikářství začíná čím dál tím více projevovat spojení politických provinění se staršími motivy tyranství, morální zvrhlostí až fantastickým padoušstvím. Svưj vrchol dosáhne tento transformační proces až po Koncilu v Basileji. Nejlépe se rozkol mezi politickou realitou v době Václavova sesa-

Ebendorfer, Chronica regum Romanorum, Pars I. In: MGH, Scriptores rerum Germanicarum N.S. XVIII. Hg. von H. Zimmermann. Hannover 2003, S. 550. 
zení a fantastickým zkreslením událostí dá ukázat na př́ikladu kauzy vraždy Jana z Pomuk, který se v roce 1393 stal obětí sporu mezi Václavem IV. a pražským arcibiskupem Janem z Jenštejna. V roce 1454 přepisuje kronikář Tomáš Ebendorfer politicky motivovanou epizodu, o které mluví i sesazovací listina, na romantickou zápletku: Z předního právníka na biskupském dvoře se tak stává zpovědník královny Žofie, který odmítá prozradit rozzlobenému Václavovi královninu nevěru. 
